\title{
Visioning event horizons: Where do we go from here?
}

\author{
Dennis Bray* \\ G KSS Forschungszentrum, GAS G eb. 38, M ax-Planck-Straße, 21502 G eesthacht, G ermany
}

\begin{abstract}
This paper suggests modeling approaches to add decision utility to climate impact assessments. It demonstrates how the Weberian sociological concept of ideal types may be modified to incorporate relevant sociological elements into otherwise rational-technocratic analyses. It proposes 2 means of implementing this approach, namely with the use of hybrid expert systems and the introduction of confidence factors, and with the use of Bayesian belief networks. No model is constructed, rather the means of operationalization are discussed.
\end{abstract}

KEY WORDS: Sociology of the environment $\cdot$ Impact assessment $\cdot$ Climate change $\cdot$ Informed decision making

\section{INTRODUCTION}

'Improving the relevance of the models to policy needs, as well as the presentation of model results to policy makers [is a major challenge to the climate impact assessment community.]

$[T]$ reatments of decision making under uncertainty $[\ldots]$ are at present poorly developed [...] especially in the climate change literature.'

(Bruce et al. 1996, p. 7)

Recent research (Bray \& von Storch 1997, 1999a, Krück \& Bray 1999) does much to confirm the existence of such a significant gap in the process of the transfer of knowledge from science to policy. Such an approach to impact assessments as proposed here, it is believed, would act to lessen that gap and aid both the priorities of the science and the priorities of policy making in the process of making informed decisions.

This paper concerns developments in methods of environmental impact analyses that would allow for the incorporation of the role of human agency and human decision making. First, the concept of environmental impacts deserves mention. The decisions regarding such impacts might concern the impact that a certain change in the physical world might have upon another aspect of the physical world, landscape for example; the impact might concern the well being

*E-mail: bray@gkss.de of humans, in terms of health, aesthetics or economics, or it might involve the well-being of other life forms, both plant and animal. Needless to say, the decisions regarding what, if anything, to do to avert change (impacts) involve a number of value judgements and an integration of a diversity of disciplinary-defined data and disciplinary-defined scientific perspectives. This paper suggests some means of combining both the data and the perspectives.

It consists of 2 parts, the first of which makes a basic assessment of some aspects of the current paradigm of environmental impact assessments, with a particular emphasis on the issue of climate and climate change impacts. Conclusions from this section include that the typical approach is linear, based on the assumption of rational action, and devoid of the role of human agency. The subsequent section reviews some current approaches which may act to rectify this matter and offers additional, complementary means of addressing these current weaknesses.

In short, the aim of the extended approach to impact analysis is to provide practical knowledge to those employing such knowledge in decision making processes. This discussion proceeds with the belief that climate change, both its impacts and consequences, will be enacted at the regional level since the globe is not homogenous in either physical or social characteristics. Consequently, I perceive that models offering 
practical advice must address the regional and/or sectorspecific levels of abstraction.

While the potential for a national economy to decline under certain conditions might be insightful, and is often stated as the outcome change, it is often stated in a manner that offers too little in detail to be of use to practical decision makers. In part this is the fault of what could be construed as disciplinary apartheid and the unwillingness of social scientists to explore new methods and the unwillingness of the natural scientists to explore new paradigms.

\section{IMPACT ASSESSMENTS UNDER SIM PLE ASSUMPTIONS OF THE SOCIAL WORLD}

To begin to address the models requires a brief discussion of the context under which they are constructed. Our heritage of 'rationality' has left us afloat with a system, or at least the desire for a system, of clean and well-defined logic designed as an effort to produce absolute answers. Unfortunately the reality is that of great complexity. Nonetheless, often logic forces us to proceed in a step-by-step manner without any reference to historic reality and more than a hint of irrelevance concerning relativism, humanism and indeed, at times, common sense. It is often under such circumstances that modeling occurs. The logic does not necessarily fall short within the natural system, but one cannot and should not assume rationality within the social system. Where the natural and social systems intersect is all too often prone to this process of oversimplification. For example, an integrated assessment model might lead to conclusions of a rise or a fall in a nation's gross national product. ${ }^{1}$ Often the resulting figure is claimed to encapsulate a national economy. Furthermore, whereas climate change assessments might indicate a rise or a fall in a particular climatological variable, temperature for example, such knowledge in isolation, or indeed, any series of noted changes in the natural world, cannot begin to address the issues of social impacts without the incorporation of social variables which themselves must address the role of human agency. After all, the character of the social impact is at last partly determined by human decisions and one hundred percent of change is mitigated by the human imagination.

To address this we could, at best, hope to provide a range of options that could occur dependent upon both change in the natural world and the whims of human-

\footnotetext{
${ }^{1}$ Questions must arise as to the validity of such claims if one considers the current inability of the science of economics to be able to predict even the daily fluctuation rates of monetary currencies, much less a $30 \mathrm{yr}$ projection of change for entire national economies dependent upon a change in climate
}

ity. Ultimately the best that could be offered is a range of possibilities, a range of event horizons, that could occur under varying sets of circumstance. To persist in single trajectories is to have inherent trappings of failure.

In many impact analyses or models, many of the results tend to anticipate a continuation of current trends, with the exception of the specific independent variable and specific dependent variable under consideration. Current trends are perceived as a natural basis for extrapolating visions of the socio-economic future. Typically they assume no other major changes will occur in the social or political or economic configurations.

At one level of abstraction such an approach works well, for example, as in agricultural impact analysis related to single climatic variables. As early as 1907, Hooker's work was directed at establishing the relationship between agricultural output and climate. Such an analysis is however limited to the impact of weather patterns on production quantities under otherwise ideal conditions, with no consideration given to the human element. Furthermore, until seasonal or annual weather variation is within the realm of prediction, such knowledge, while providing a great degree of insight, remains grounded more in academic knowledge than in practical knowledge; that is, knowledge that can be employed by those whose livelihood is dependent upon agriculture and crop yields is not contained within the results. For example, to tell a farmer that his crop will not grow in the absence of precipitation is not earth-shattering news to a farmer. Nonetheless, research progressed in this manner. This is not to say the research is unnecessary, on the contrary, but such 'answers' are not an ends in themselves if such knowledge is to be of practical use. The farmer would need to know, among other things, 'predictions' of precipitation patterns in order for knowledge of the relationship to have any utility.

By 1924, Fisher introduced regression techniques that became a standard for stating agricultural impacts. By 1983, Waggoner put forth a standard method for such an analysis incorporating technological advancement:

$$
Y_{i}=a+b_{1} t_{i}+b_{2} X_{2 i}+\ldots b_{n} X_{n i}
$$

where $Y_{i}=$ estimated yield in the ith year, $a=$ intercept, $t_{i}=$ surrogate for technology in the ith year, $b_{1}=$ coefficients representing the effect of technology in quintals/hectare/year, $b_{2}$ to $b_{n}=$ coefficients representing the effect in quintals/hectare/unit change in weather, $X_{2 i}$ to $X_{n i}=$ weather variables such as precipitation, temperature, potential evapotranspiration (PET) and evapotranspiration (ET) in the ith year (adapted from Nix 1985, p. 111).

It is not the intention here to argue the method of the determination of agricultural yield under different 
expressions of weather or technological improvements, but simply to point out that if the assessment of future crop yield under changing climatic conditions is the desired outcome, then $X_{2 i}$ to $X_{n i}$ are arbitrary, since under the current state of climate change knowledge, regional climate change predictions are all but absent and under the state-of-the-art meteorological forecasts it is unlikely that anyone would claim to make annual forecasts with anything other than qualitative statements, far short of the accuracy necessary for the above equation. Furthermore, neither can technological advance be little more than an informed assumption at best. As such, such an analysis, while providing scientific insights, is little in the way of practical advice for farmers. Yet this approach is often applied to impact analyses and is readily accepted by both the scientific and policy making communities. It is not, however, my intention to discuss the already existing body of literature, pointing out the weaknesses of current impact assessment studies. What I hope to have demonstrated with the above example is a basic flaw which seems in many ways to be perpetuated. This is not to criticize such methodology, for it accomplishes its task admirably, demonstrating the relationship between precipitation and crop production. However, it remains only the first step in a complex discussion. While it is conclusive as to the relationship between the 2 variables - precipitation and harvest - it is insufficient to represent the potential of future realities under changing climatic conditions if the intention is to demonstrate a comprehensive vision of the potential futures under conditions of climatic change. It requires the caveat all else being equal (with the exception of the attempt to account for the impact of technology). Such an assumption however does not approximate reality. Simply put, such an analysis allows for the conclusion that if the manifestation of climate change was to produce such and such a result, then we might expect this as a partial impact on agriculture.

Even with the advent of large-scale computer models, similar problems are inherent, as indicated in the AGREC Core project of PIK (Potsdam Institute for Climate Research) for example. The project is described (see Website sections 3. Intermediate Results, 3.11 Problems and 3.1.3 Results and Discussion, respectively) as having a 3-fold goal:

'1. Evaluation of a statistical method for estimating Climate Change Impact on national mean yields for wheat, potatoes and maize. [One should note here that the calculation of climate change can, to repeat, be no more than a guided assumption.] 2. Regional simulation of wheat yield response in Brandenburg on a transient climate change scenario. [One should note here the assumption of climate change trajectories is broadened and applied to a regional context, an ability well beyond the current state of the science.] 3. Evaluation of a statistical method for estimating climate change impact on German national mean yields for wheat, potatoes and maize.'

To begin the process of achieving these goals, the scientists claim:

'... we tested a simple regression approach, which relates weather of several climate stations of a country to the national yield and use this relationship to predict the yield effect of a homogeneous climate change within the country. This, of course, implies the correlations are tested against existing conditions. The method was originally developed in order to deliver early predictions of national yields based on weather data and was successfully used both by German and European Bureaux [sic] for Statistics (Hanus 1969, 1978). Even though the use of regional climate change scenarios is still exceptional, the "homogeneous change" assumption uses this method to provide first impact estimates of GCM scenarios where no further downscaled scenarios are available. In order to test the method, a model was calibrated and then used to estimate German national yields of wheat, maize and potatoes for the reference period 2070-2099, using the HADCM 2 climate change scenario of the Hadley Center for Germany which assumes [emphasis added] a $\mathrm{CO}_{2}$ increase to a mean level of 800 ppm (Mitchell et al. 1995).'

The report continues

'The results are plausible and accord with results of other studies for similar scenarios (Harrison et al. 1995). The climate trajectory (not shown) for the HADCM 2 scenario clarifies a temperature increase at almost constant precipitation. [and] The climate change scenarios are part of a transient climate change scenario for Brandenburg provided by the climate department of PIK (Gerstengarbe $\&$ Werner 1997) which assumes [emphasis added] a mean temperature increase of $1.5^{\circ} \mathrm{K}$ to $2050 .^{2}$

(http://www.pik-potsdam.de/cp/agrec/info_4.htm)

It should be noted here that the assumptions are, indeed, well noted by the authors, but it is often the case that such assumptions are overlooked by others when evaluating the research results. The assumptions themselves have become standardized measures, and are readily accepted among the evaluators of the research, although the assumptions are, as stated, well noted among members of the climate sciences.

I would like at this point to present yet another conclusion drawn in an agricultural impact analysis, conducted in 1993, which extended to the year 2050 (Harrison \& Parry 1993). It is presented neither as a criticism of the methodology nor as a criticism of the conclusions drawn. Rather it is presented to emphasize again that a great many assumptions are incorporated into accepted approaches to such research, perhaps justifying my claim for the incorporation of social assumptions in future modeling attempts.

'A number of scenarios were constructed to assess the effects of climate change on agriculture and horticulture in the EC. Composite time-dependent scenarios allowed for

\footnotetext{
${ }^{2} \mathrm{~N}$ ote that at the Web site full references to work included are not available and are consequently not provided here
} 
assessment of the possible rate of change in crop response. Results from individual GCM s showed considerable differences both in the magnitude and sign (positive and negative) of crop response to climate change. None of the GCMs used to construct the scenario are yet sufficiently reliable to provide predictions of the future changes in climate variability and large uncertainties remain in their representations of climate at fine scales of resolution.

The scenarios provided average changes in climate, from which crop responses were calculated. However, it is well established that many of the relationships between crop growth and environment are non-linear.

[...]

Despite uncertainties in the results there are important implications that arise from this study. There is certainty about some crop responses. Warmer temperatures will shorten the duration of the growing period for annual crops. It is now clear that the net result of this is decreased yield, although the direct effects of increased $\mathrm{CO}_{2}$ will offset this for some crops such as wheat. Conditions in southern Europe will generally become hotter and probably drier. [...] Parts of Western Europe may benefit if there is an average increase in precipitation.'

(Harrison \& Parry 1993, p. 187-193; emphasis added)

One must note at this point that the above are crucial first steps in assessing any future impacts related to, in this instance, climate change and agriculture. However, one must be aware that they are first steps and provide little in terms of practical knowledge for those who are likely to experience the impact. In the following section I would like to make some suggestions that would assist in the provision of, or at least provide an addition to, such knowledge.

\section{VISIONING EVENT HORIZONS}

In this section I would like to expand the concept of impact analysis as discussed above to incorporate some aspects of human agency and the notion of ranges of proactive and reactive choices which have the potential to produce ranges of outcomes. In short, the desire is to present a number of trajectories, incorporating the roles of culture, society and human agency, the subject matter of social sciences as defined beyond the disciplinary limits of economics. The limitations of a single paper, however, do not allow for a full discussion of the details of these roles.

Typically the individual aspects of broad sociological concepts are not amenable to the reduction of discrete variables. Nonetheless, the boundaries can be delineated by the sociological concept of ideal types and each ideal type could, if necessary, be assigned a value. (For example, if one is concerned about the influence of public environmental attitudes, then a high level of concern could be assigned a level of 1 and indifference could be assigned a level of 2.) The Weberian concept of ideal types relates to the abstrac- tion and exaggeration of defining characteristics so as to form coherent intellectual constructions. ${ }^{3}$ Not all characteristics of an ideal type are always present in the real world situation but in the situations under question they act as a means of comparison. Ideal types remain as hypothetical constructions, formed from real phenomena and which have explanatory power. ('Ideal' in this sense refers to an abstraction, not to that which is normatively desirable.) In this discussion ideal types are employed simply to depict possible ways in which events could unfold over time.

Furthermore, often in environmental impact assessments the environmental variable is assigned a deterministic quality superceding all other potential causal paths, and, more often than not, is determined to have a direct effect or minimally an indirect effect. Here I propose that the natural/physical variable can also be assigned a role more in line with an interaction effect. For the purpose of clarification, a direct effect occurs when a changed value of independent variable changes the value of a dependent variable, and an indirect effect occurs when an independent variable has an effect on a dependent variable via an intervening variable. The intervening variable helps explain why the independent variable affects the behavior. An interaction effect, on the other hand, refers to the situation where 2 or more independent variables act in combination to produce the resulting effect on the dependent variable where the effect of either independent variable will vary according to the value of the other independent variable. For example, the impact of an extreme weather event will interact with public sentiments (high versus low environmental concern) in the formation of subsequent policy. In short, the manifestation of the impact of climate change is dependent on both the climatological reality of climate change and the perceptions of the climatalogical reality. Perceptions, I argue, can be an independent variable in many cases and in some cases have the potential to play a more significant role that the natural-world variable in question. ${ }^{4}$

\footnotetext{
${ }^{3}$ Weber '... subordinated sociology to the task of showing the elements out of which history is made. For this purpose he created ideal types, abstract models of bureaucracy, class, markets, and so forth, that could capture an aspect of the complex historical reality, always keeping in mind that several ideal types would have to be applied at once to capture the various sides of things. These ideal types have become the germs of post-Weberian sociology. Each one is a kind of encapsulated theory, much in the same way that the chemical table of elements is a theory of how molecules are put together. Weber denied that there were laws for the overall pattern of history. How that went depended on just which combinations of the 'molecules' were put together in each case.' (Collins 1994, p. 85-86)
} 
Making claims for the necessity to incorporate the 'social' and the 'natural' into a single analysis are numerous. ${ }^{5}$ Too often however the claims run short of providing any insight as to the means of the operationalization of such claims. To this end, I would now like to turn attention to a discussion of how such claims might be meaningfully integrated into what could be termed a model.

\section{OPERATIONALIZATION}

As with all research methodologies, it is necessary to begin by stating the assumptions of the methodological approach. These are merely assumptions I deem necessary in an effort to provide practical knowledge.

(1) For comprehensive impact analysis, it is not possible to separate the sector-specific interest from the geographical region in which it is located and still maintain the level of abstraction necessary for the meaningful consumption of knowledge. For example, climate change impact on agriculture must also include some meaningful boundary of where the agriculture is undertaken. This boundary might be based on cultural practices and/or social values, proximity to markets, etc.

(2) Geography contains cultural specificity, regional cultures differ, and it is regional cultures that mitigate the regional process and subsequent regional impact, and they may do so in a different manner than other regions experiencing the same climate impacts.

(3) Human agency determines the integration and mitigation of the impact, and climate and climate change are not overly determinant with the exception of extreme events.

(4) Incremental time steps (process as opposed to the end states) play a significant role in the eventual outcome. As such, timing (of events, perceptions, decisions, etc.) is a critical variable.

${ }^{4}$ For an example of the perceptions of climate scientists see Bray \& von Storch 1997,1999a,b; for an example of the perceptions of policy makers see Krück \& Bray (1999); for examples of public perceptions in the USA see Kempton (1995) and public perceptions in Europe see (Gooch 1995), or for a selection of global perceptions according to nation see Dunlap (1993)

${ }^{5}$ See for example, the critique of Hasselmann's GES (Global Environment and Society) model (Hasselmann 1990) by von Storch \& Stehr (1997b), who present a PES (Perceived Environment and Society) model. While the GES model was indeed submitted to analysis, no means is however presented as to how to operationalize the PES model. One has to acknowledge however, the fact that one first has to have a concept of some quality before being able to determine a 'quantitative' expression of it. However, many such attempts never extend beyond conceptualization
The method must also attempt to address the human dynamics of process as it might come to bear on the outcome of change. The dynamics of the process infers the incorporation of human choices and decisions. Furthermore, decisions are both temporally and spatially located. Consequently, a major characteristic of methodology is the consideration of sequential change potentials through the lapsing of time, where a different choice at one time horizon might produce different results at succeeding time horizons, and choice might be based on the combination of regional beliefs and broader societal beliefs. For example, the experience of climate at any given time will come to bear on human decisions, at times pushing climate and climate change to the forefront of consciousness, at other times being a forgotten consideration; both of these situations have the potential for different outcomes and both the potential to occur under the same long-term gradual pattern of climate change. So too will the presentation of 'authoritative' sources of information rather than visceral experience come to bear on perceptions and interpretations.

Of course, in applying the approach suggested herein to a concrete example, one is forced to make arbitrary selections of the possibilities of what form these perceptions might take and what factors might come to bear on the range of possible decisions. Consequently, one is forced to draw from a range of change potentials occurring in the natural world and a range of change potentials occurring in the social world. For example, if $x$ change occurs in a natural variable, how might it bare out in its social interpretations and contexts, and how might these social interpretations and contexts impact on the eventual outcome? Here, one is forced to determine a plausible range of social interpretations and also draw from the range of possible changes. One way to address this problem is the opposites contained within an ideal type. One should note that suggested or hypothesized changes to climate are no more facts than the suggested or possible changes in the social process of climate change. ${ }^{6}$ On the contrary, both are limited to being no more than informed selections of data, the former being neither more truthful nor more accurate.

The temporal aspect of this approach contends that impact analysis must be incremental with feedback loops derived from temporally located decisions and in situ circumstances, the time delineation being arbitrary but determined in a meaningful sense. Since climate change is now suggested as being a slower process than first estimated, to exemplify the methodology, selection These should be meaningful in terms of human experience. Ultimately, the delineation of the time horizons should approximate the time horizons of the knowledge consumer, for example, corporate time 
horizons, the "environmentalists" time horizon, policy time horizons and the time horizon of a small business operator are all likely to differ and models should be adjusted accordingly.

The larger culture and society in which the change is occurring must also be disaggregated according to vested interests. For example, the assumptions of the political sphere, the scientific community, the industrial sector and the lay person do not necessarily converge, and the assumptions of each will come to bear on each other and the eventual outcome of climate change. (Neglect of such aspects has often resulted in prolonged stalemates in the decision process.) This disaggregation is also prone to differ according to geography (and perhaps time). For example, the local influence of science might play a weaker role in lesser developed countries than in developed countries (i.e. north-south hemispheric relations) or in national regions (e.g. 'east' vs 'west' Germany) or a lesser role in regional actions-reactions than at the national level (see Bray 1998a,b). Environmental concerns might also, for example, play a greater role at times when economies are stable etc.

In the case of climate change, since prediction of regional-local climate change conditions are not yet available in most cases, those employing what is suggested here as an approach to assessing impact potentials would be best advised to utilize the possibility of the extreme range of trends rather than a single and typical increase of $x^{\circ} \mathrm{C}$ or an $\mathrm{x}$ change in precipitation

\footnotetext{
${ }^{6}$ Such ranges of climate change possibilities are often present without geographical specification and, indeed, are presented as ranges between $x^{\circ}$ and $y^{\circ}$, for example. Since such specification is beyond the current abilities of the natural science, it suggests a continued or perhaps increased need for research efforts in areas related to downscaling, if climate change is perceived of as a legitimate threat. For example, IPCC (1996) report states (p. 4) 'A general warming is expected to lead to an increase in the occurrence of extremely warm days and a decrease in the occurrence of extremely cold days' and 'Warmer temperatures translate into prospects for more severe droughts and/or floods in some places and less severe droughts and/or floods in other places. [Which places? Warmer or cooler?] Some models suggest more extreme rainfall events. Knowledge is currently insufficient to say whether there will be any changes in the geographical distribution of severe storms.' Regarding regional levels, a minimal level necessary for meaningful dialogue, we are informed (p. 290) that in regard to projections of regional-scale climate changes, we can expect by the year 2030 'temperature changes between $0.6^{\circ} \mathrm{C}$ and $7.0^{\circ} \mathrm{C}$ and precipitation changes to range from $-35 \%$ to $+50 \%$.' In short, there is much less than specificity and this, of course, is well noted by the members of the climate sciences (see Bray \& von Storch 1997,1999a,b). This is no reason however to delay the development of impact analyses for regional concerns in terms outlined here. It does however demand that a number of possibilities be considered
}

patterns. For the example of the German coastal region, we find mention of the possibility of both warming and cooling trends requiring that both possibilities be considered in the development of the subsequent series of event horizons. Should, however, the region of focus be considered to be an area that is prone only to experience a warming trend, for example, the researcher must still consider such aspects as the magnitude of change, the process of the change, the speed of onset, the qualitative characteristics of the process such as rapid variation and a rapid return to climatic stability, etc. In short, the available assessments from the natural sciences are transformed as well as possible into the representation of the potential experiences. Furthermore, there is no reason not to employ a similar process regarding perceptions and the decision making processes, drawing what-if outcomes from a range of possibilities, these possibilities being drawn from range of meaningful social trends. For example, even in the absence of real change, the perception of change may act as a human catalyst for action. With this in mind it becomes necessary to acknowledge the experiential reality and typical flow of information in this regard.

To be fully comprehensive would ideally require a study of historical trends and broader social characteristics, and behavior in a particular region would be best understood in the context of broader societal patterns. Further, it should not be forgotten that a geographically defined community cannot be studied in isolation any more than a single type of grain production under changed climatic conditions can be separated from the broader context of agriculture practice. In addition, under ideal circumstances, knowledge of the intervening factor (climate change) must al so be in sufficient detail as to estimate the potentials for change. In short, we are confined to making conjectures defined as an 'if-then' proposition in which 'the if is stated at the outset while the then is inferred and examined on the basis of implications inherent in the if.' (Bowles 1981, p. 16). Such an approach has its main purpose as being a means of 'disciplining the imagination and for making broad inferences about an uncertain or unknown future.' (Vlachos 1977, p. 211).

At this point, for the sake of example and clarity, I will address such an approach to impact analysis as it might address the issues of climate change impact. The approach, however, I will emphasize, it not limited to climate change impacts but has the potential to address any impact assessment related to future potentials. In line with the determined necessary assumption noted above, one must first determine 'Climate impact on what?'; in other words, what is the sector/socialspecific phenomenon or entity that one wishes to address. For example, we should avoid the pitfalls of 
attempting to determine 'the impact of climate change on the coastal region' for it begs the question 'What aspects of the coastal region?' There can of course be successive studies addressing different issues leading to a comprehensive analysis. There is also a similar tendency with the sector-specific level of abstraction that should also be avoided. Consequently, one must determine levels of abstraction and delineation. Having done so, it is then necessary to determine the most meaningful weather/climatic expressions that may come to bear on the topic at hand and subsequently gather the most current climatic/weather assessments of these expressions for the region. For this example I will choose the impact of climate change on tourism for the coastal region of Germany (see Bray 1998b).

Before assessing the manifestation of climate change for the geographic region it is necessary to determine what features of the climate are important for the topic being considered. ${ }^{7}$ In the example noted above, tourism industry managers and tourism experts were consulted. The number of sunny days in N ovember, for example, proved to be an insignificant factor, as did mean annual temperature or mean annual precipitation, etc. What proved to be relevant for tourism, according to the experts, was mean temperatures, number of rainy days, number of summer days and number of pleasant days (determined by the definitions of the Deutsche Wetterdienst-the German Weather Service) for the months M ay through September. With this in mind, it was necessary to establish a climatic baseline from which to assess change, namely the pertinent climatic features. 'Climates' for many regions contain the necessary data for the task at hand. Having compiled a baseline, the next step was to determine potential patterns of change.

The search for climatic data pertaining to regionallevel change resulted in less than satisfactory results. Consequently regional trends were based on possibilities rather than scientific assessments. These possibilities were within the realm of global trends and trends suggested for the region in question, in short, ideal types of climate change. Three possibilities were drawn from the natural sciences: (1) a gradual warming of approximately $3^{\circ} \mathrm{C}$; (2) a pattern of extreme vari-

\footnotetext{
${ }^{7}$ In this case, based on the work of Lohmann (1998) and Feige (1998), tourism experts, 4 climate features were deemed as particularly relevant for tourism: (1) the mean monthly temperatures for the months of May through September; (2) the monthly number of 'summer' days for the months of May through September; (3) the monthly number of days without rainfall for the months of May through September; and (4) the monthly number of 'pleasant' days for the months of $M$ ay through September; all of those are beyond the limits of prediction
}

ability around a mean increase of $3^{\circ} \mathrm{C}$; and (3) a gradual cooling of approximately $3^{\circ} \mathrm{C}$. (Note that the assumption is made that climate is indeed going to change. However one could just as easily incorporate a pattern of no change, assessing only the impacts of the perception of change.)

Since the knowledge of climate change is not developed well enough to provide accurate estimates of longterm weather patterns, to calculate possible change patterns for the years 2000 to 2030 (the time period selected for the study) for each proposed pattern of change and each selected variable, a quasi-random number generator was designed to approximate, in each case, the desired change pattern, projecting from the existing climatic mean value into the future around the predetermined trend, namely the possible climatic ideal types. That is, the range of variance was designed to fit within the parameters of a predetermined change of a gradual $3^{\circ} \mathrm{C}$ increase over a $30 \mathrm{yr}$ period for the first climatic ideal type, a gradual increase over a $30 \mathrm{yr}$ period reflecting rapid periods of climatic fluctuation resulting in a mean increase of $3^{\circ} \mathrm{C}$ for the second ideal type, and a gradual $30 \mathrm{yr}$ decline in temperature resulting in a mean decrease of $3^{\circ} \mathrm{C}$ for the third ideal type. In this sense, the patterns are not truly random but are random within the predetermined parameters. (However, data for the time period 1960 to 1998 reflect recorded observations.) The succeeding years are designed to emulate ideal types of climate change patterns. These are depicted, for the purpose of the example, in Fig. 1.

Similar constructions were made for the other 2 climate change possibilities. No consideration was given to the physics of the climate, and, furthermore, none was necessary since it was not the purpose to determine the exact nature of the reality of climate change per se but rather to depict possible trends from which to make other assessments. This, of course, is similar to saying 'if climate changes as such, crops will respond as such'. Both cases make the assumption of 'if climate changes this way ...' and this will have to suffice until such times that climate science is advanced enough in the skills of downscaling to produce a more accurate depiction.

Other related variables that were determined to have the potential to have an impact on tourism as it relates to climate change included the roles of science, the media, regional policy, national policy, national business interests, national demography, regional demography, transportation developments, landscape developments, microeconomics and macro economics both at regional and national levels, official eco politics, and public eco politics. Each of these items was in turn assigned the characteristics of ideal typical divisions, for example, high levels of media attention versus low 
Mean Monthly Temperature for Months May - September

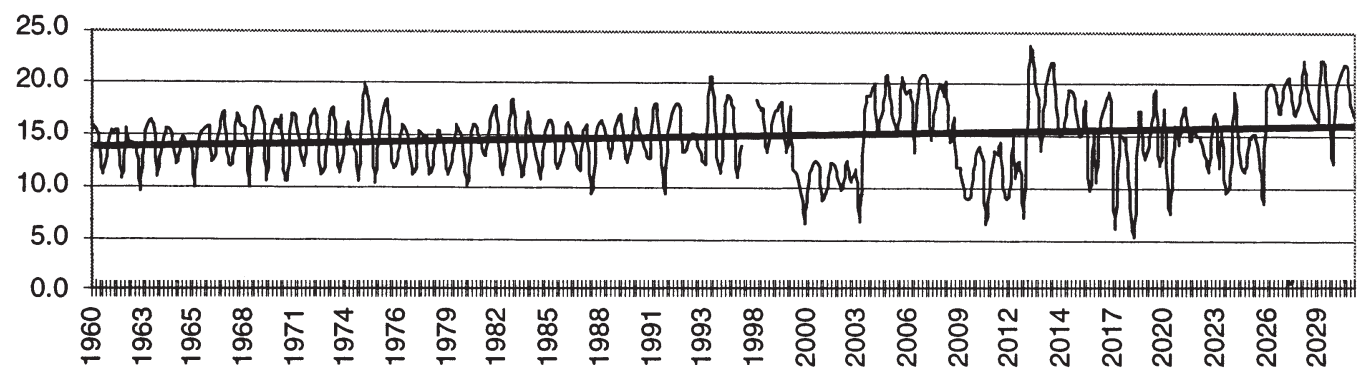

Number of Days with Rain for the Months May - September

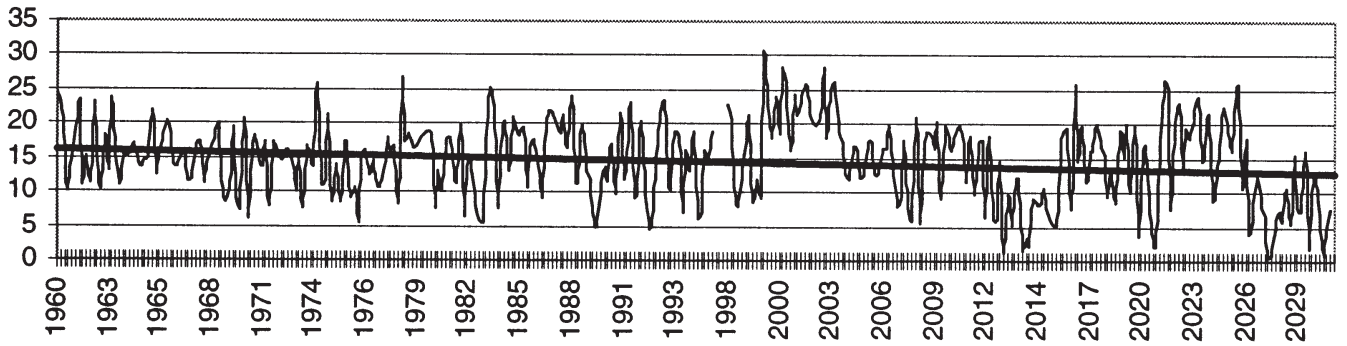

Number of Summer Days for the Months May - September

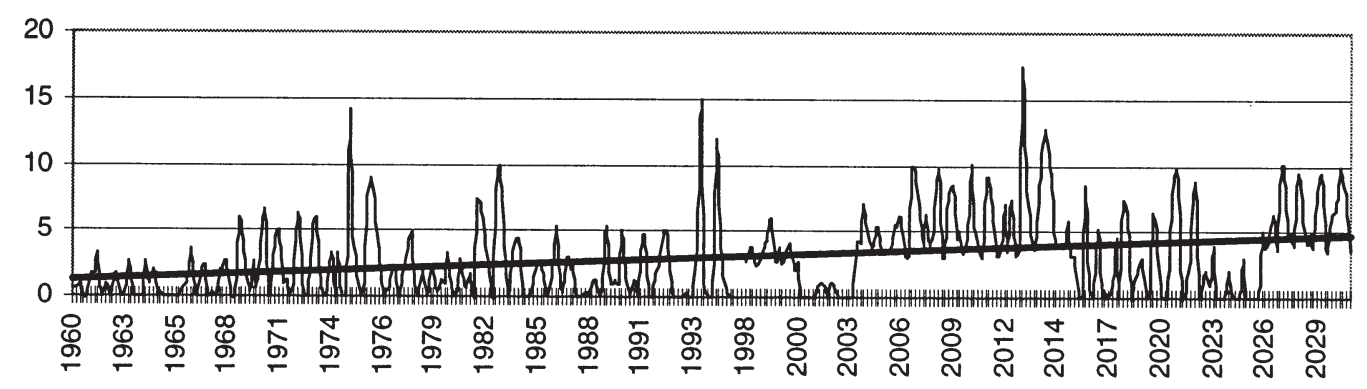

Number of Pleasant Days for the Months May - September

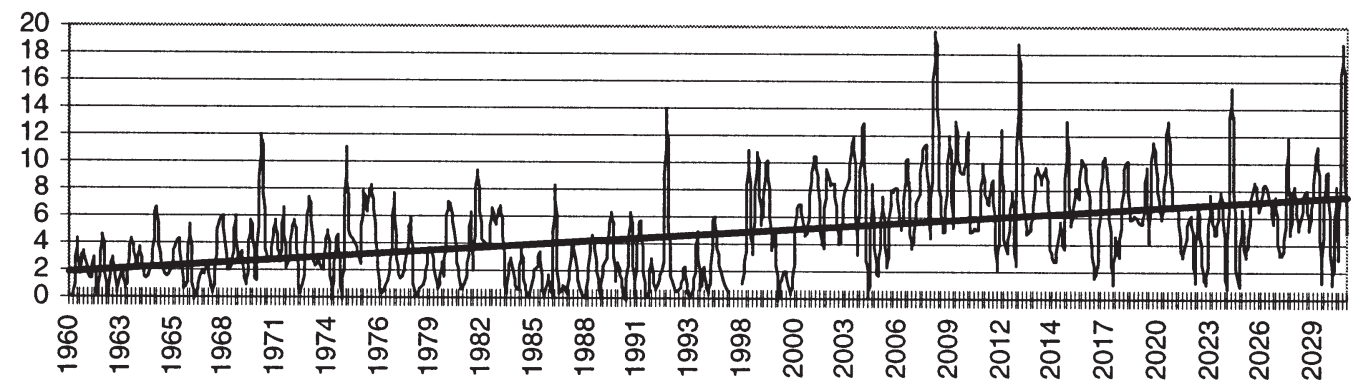

Fig. 1. Ideal type: rapid climate fluctuation with an overall warming tendency for a $30 \mathrm{yr}$ period 
levels of media attention, high level of environmental concern versus low level of environmental concern, etc. The actions and reactions of each were assessed with $10 \mathrm{yr}$ intervals for the period of $30 \mathrm{yr}$. The project in this instance was designed to present a qualitative narrative. I would at this point like to discuss the possibility of extending such a narrative to a quantitative modeling approach with the possibility of 2 options, namely a hybrid expert system and a Bayesian belief network.

\section{TOOLS FOR ANALYSES}

The variables involved and the relationships among the variables would first need to be presented in a schematic fashion for the sake of conciseness. This would enable the development of a hybrid expertsystem to be employed as a heuristic tool. Typically, expert systems are built as a practical tool for decision makers. In this case the intention would be to provide insights as to what to expect in the broader wake of the climate change issue. The depth of insight is, of course, limited to the imagination and to the resources allotted to the project.

At its simplest, a rule-based expert system is based on sets of IF-THEN rules. IFs are called the antecedent (or condition) and THEN s are called the consequent (or action). Again, it is necessary to state that in this example I am dealing with events that may occur in the future and with relationships in much need of further empirical investigation. Nonetheless, each rule should be designed with the belief that the antecedent implies the consequent. The antecedent (or the consequent) or the rules may also contain conjunctions and disjunctions of the premises. For example, one could employ Boolean logic, which deems an antecedent to be true when all of its conjunctive conditions are true, or a disjunctive condition to be true when one of its elements are true. Such a system, however, in not necessarily confined to the limitations of Boolean logic.

\begin{abstract}
'Rule-based models have three structural components: A knowledge base, a working memory, and inference engine (or rule interpreter). The knowledge base contains the set of IF-THEN rules that the model will use to reason about input information. Working memory serves as a scratch pad for keeping track of initial conditions and all inferences that have been made. The inference engine contains processing mechanisms that combine the implicational beliefs in the knowledge base with the believed "facts" in working memory to produce new beliefs. These beliefs are then added to the list of "known facts" in the working memory.'
\end{abstract}

Taber \& Timpone (1996, p. 41-42)

There are 3 basic tasks necessary to construct such a system: first, and perhaps the most difficult, is the determination of the knowledge to be used in the domain of interest; second, this knowledge must be precisely expressed in the knowledge base; and third, consideration must be given to the design the inference engine. While Steps 2 and 3 are, for all intents and purposes, logical tasks that require logical solutions, the first step naturally requires the input of the expertise of the case under consideration. For example, in the case of the impact of climate change on tourism for a specified region, one must acquire the expert knowledge regarding the possible manifestation(s) of climate change for that particular region, the nature and characteristics of the tourists of that region, and, with the assistance of tourism experts, other influential factors regarding tourism. It is necessary, for example, to determine as best as possible what criteria are important in the holiday decisions of potential tourists, what elements of the climate/weather are deemed as important, the characteristics of facilities, costs, etc., namely, the process of selecting a holiday destination as well as the impact of policy options. In short, one must provide the base knowledge to be incorporated into the structural components of the model.

After collecting the knowledge, typically in a knowledge based system the next step of development is to express the knowledge gained in the form of production rules. Here the construction of the suggested model differs from the typical process of expert-system development. In this proposed approach of assessing future impacts, each rule or reference, while determined as a logical process, is hypothetical since it is based on future 'possibilities', not past realities. (Nonetheless, I contend the detailed specificity of past relationships is not beyond disciplinary ability.)

The same limitations apply to the task of building the inference engine where the basic mechanism is inference chaining. This particular example of application could infer, for example, IF the climate does not manifest any experientially notable changes or events AND the media pay little attention to the phenomenon of climate change THEN public concern and policy concern for the issue may decline. This is not to say that climate change is not occurring or will not occur, only that there is a general tendency not to acknowledge the fact, and perhaps this raises the potential for catastrophe at a later date. The inference engine must, of course, include as many combinations as the imagination and resources will allow.

Further possibilities for making the system more interactive for the user and relationships more detailed in the absence of statistical or mathematical relationships, could be devised using what is known as the CF method. 
'In this approach, every element $\alpha$ in a working memory has a certainty factor (CF) that measures the system's degree of belief $M B(\alpha)$ and disbelief $M D(\alpha)$ in the element, such that $C F(\alpha)=M B(\alpha)-M D(\alpha)$. MB $(\alpha)$ and $M D(\alpha)$ vary between 0 and 1 , and $C F(\alpha)$ ranges from -1 to +1 . $C F(\alpha)=1$ means that the system is certain that $\alpha$ is true; $\operatorname{CF}(\alpha)=0$ means that the system is unsure; and $\operatorname{CF}(\alpha)=-1$ means that the system is certain that $\alpha$ is false. This seemingly odd method allows human experts to assess belief and disbelief as independent dimensions, which are not allowed by probability theory.

[...]

Typically, the CFs for input conditions or goals in an expert system are supplied by the user. Each rule $\mathrm{R}$ in the knowledge base also has a certainty factor $C F(R)$, derived during knowledge acquisition. Consider the rule IF $\alpha$ THEN $\beta$ with $C F(R)=3$. The CF method calculates belief in a new inference $C F(\beta)$ as the product of the CFs for the rule $\mathrm{R}_{1}$, and the antecedent condition $\alpha$ (assuming forward chaining). So if $\alpha$ exists in a working memory with $C F(\alpha)=0.6$, rule $R_{1}$ will fire and place $\beta$ in working memory with $C F(\beta)=.18$

Taber \& Timpone (1996, p. 46)

Such an approach would allow tourist experts to assess their own set of beliefs as well as to interpret the role of social perceptions of climate change.

The final extension of such an approach to impact analysis has only recently been made possible by the advent of readily available computer power and advances in statistical algorithms. Using the above delineation of the components of an impact, one could construct Bayesian Belief N etworks that allow outcomes to be assessed under differing conditions, both physical and social, and under different decision processes. In their study Valverde et al. (1999) set out to 'present a policy-oriented, integrated decision analysis framework that focuses on the fact that decisions about greenhouse gas control are not made once and for all; current policy choices will be reconsidered in future years in light of new data and improved understanding of the problem.' (p. 87). The authors emphasize the 'sequential ' nature of climate decisions as suggested in the above passages. They do not however, detail the roles of societal elements.

Decisions regarding the impacts of climate change in both the social and economic real ms are typically characterized by diversity and multiple levels of uncertainty. Compounding the difficulty of making decisions is the fact that decision input is drawn from both objective and subjective criteria, and often it is the subjective statements that are of great interest to policy makers. To arrive at an informed decision it is crucial to be able to combine such diverse types of evidence.

A key feature of a Bayesian Belief Network is that it forces the analyst to expose all assumptions about the impact of different forms of evidence. This means that the social implications from as far a field as the imagination would care to wander could theoretically be integrated into a single assessment, as could physical factors. In terms of practicality, one would of course draw some limiting boundaries. In this sense such a project could result in a more informed and comprehensive depiction of the socio-economic impacts and implications of climate change, incorporating the interactions of both social and natural variables.

The main use of such a methodological approach is to observe probabilities of as-of-yet unobserved events, precisely the nature of the phenomenon of global climate change. The use of Bayesian inference allows us to demonstrate that observation alone cannot predict the probability of unobserved events. In the Bayesian interpretation, a probability describes the strength of the belief which an observer can justifiably hold that a certain statement of fact is true (subjective probability). This is essential when we are dealing with the process of human decision making, particularly in those instances when there is a high degree of uncertainty as to the nature of the phenomenon. While it is beyond the scope of this paper to detail the process of implementing such a network, it is sufficient to say that the previous discussion and dissection of the climate change impact process is sufficient to suggest a structural foundation for such an undertaking and that Bayesian Belief Networks could play a significant role in assessing the impacts of climate change on socioeconomic sector-specific entities.

\section{CONCLUSION}

Taking the above approach to impact analysis implies that broader social aspects be given more consideration and be presented as a series of options, just as temperature and precipitation are presented according to the output of this or that model of climate change. The variations in both cases, both natural/ physical variables and social variables, can be treated as no more or no less than guided assumptions. Whereas 'temperature' has the option to vary from general warming to general cooling trends, perspectives of social actors can also swing between, for example, from an overarching emphasis on environmental concerns to a total disinterest in environmental concerns.

The output of computer simulations of regional climate impact assessments might be on very weak foundations, based on 'if this-then that' reasoning. Of course, this provides insight into a limited number of factors of first-order impacts (an $x_{p}$ increase in precipitation or an $x_{t}$ increase in temperature will result in a change in $\mathrm{y}$ ), an approach typically employing the deliberate and systematic manipulation of particular variables while everything else is perceived as being 
irrelevant. Such an approach is particularly beneficial when dealing with natural variables governed by natural laws, but it does not represent the social reality. In fact, it does not even acknowledge the social reality. The 'if this' is no more than an assumption from within a range of possibilities, and the end state of the impact analysis is based on many other contributing factors being held constant. By implementing the methods outlined above it is now possible to include the rich contexts in which the problems present themselves.

Furthermore, employing such methods allows us to address not only the social impacts of changes in the physical world but also the role of human agency in mitigating change. For example, if people perceive climate change as such, whether politicians, farmers or the general public, is not so readily incorporated into the typical impact analysis and the power of mere belief operating through human agency is lost. The results of their actions (while given great precedence in the derivation of climate change, for example, in regards to the production of emissions etc.) have been afforded little relevance in the subsequent studies of the proposed impacts of the climate change scenarios. Yet human perceptions, human actions and human decisions have the potential to produce results at least equal to any climate change. (A good example, for those in doubt, is presented by M cGovern [1979, 1981] regarding the decline of Norse Greenland in the wake of climate change.)

It is also obvious that such an approach does not provide conclusive quantitative evidence. Nor is this the intention, and nor, given the uncertainty of climate change, is it possible. Such an approach is designed as a heuristic tool for the specific needs of a specific consumer. The objective of the model is to provide some insight into the options of the broader circumstances that might unfold as a result of the climate change issue.

Finally, from the sociological perspective, such an approach forces the research not only to state insights and analogies with the precision and rigor of a formal language but demands the inclusion of both of the disparate voices that sociology has developed in response to climate change. That is, it demands the incorporation of both the neo-realist and interpretive approaches to the issue. In an attempt to demarcate this distinction, Redclift \& Benton (1994, p. 2) state that sociological research regarding climate change tends towards 'critical self reflection, on the one hand, and direct demonstration of the substantive insights which can already come from the application of social scientific methods and concepts to environmental issues, on the other.' A combination of both approaches are demanded as being necessary for a meaningful interpretation, and both approaches have a significant role in the development of such an impact assessment. The neo-realist approach in conjunction forces the specification of the meaningful impacts that climate change may impose on society, while the interpretive approach forces the specification of the role of actors. Since neither are exclusive categories in terms of societal effect, their combination goes towards the development of a comprehensive understanding of the social process of climate change.

\section{LITERATURE CITED}

Bowles RT (1981) Social impact assessment in small communities. Butterworth, Toronto

Bray D (1998a) Science and susceptibility: a historical comparative analysis of the years of cholera and the years of climate change in Hamburg. GKSS 98/E/61, GKSSForschungszentrum Geesthacht $\mathrm{GmbH}$, Geesthacht

Bray D (1998b) Visioning event horizons: global warming, the German coastal region and tourism. Prepared as part of 'Küstentourismus und Klimawandel' for the Bundesministerium für Bilding und Forschung, Berlin. GKSS, Geesthacht

Bray D, von Storch H (1997) The climate change issue: perspectives and interpretations. Proc 14th Int Congr Biometeorol 3:439-450

Bray D, von Storch H (1999a) Climate science and the transfer of knowledge to public and political realms. In: von Storch H, Flöser G (eds) Anthropogenic climate change. SpringerVerlag, Berlin, p 281-322

Bray D, von Storch H (1999b) 'Climate science. An empirical example of postnormal science'. Bull Am M eteorol Soc 80: 439-456

Bruce J, Lee H, Haites E (eds) (1996) Climate change 1995: economics and social dimensions of climate change. Cambridge University Press, New York

Collins R (1994) Four sociological traditions. Oxford University Press, New York, Oxford

Dunlap RE, Gallup GH J r, Gallup AM (1993) Health of the planet results of a 1992 International Environmental Survey of citizens in 24 nations. The George H. Gallup International Institute, Princeton, NJ

Feige M (1998) Küstentourismus und Klimawandel. Prepared as part of 'Küstentourismus und Klimawandel' for the Bundesministerium für Bilding und Forschung, Berlin. Deutsches Wirtschaftswissenschaftliches Institut füt Fremdenverkehr eV an der Universität München-DWIF - Büro Berlin

Fisher RA (1924) The influence of rainfall distribution on the yield of wheat at Rothamstead. R Soc Lond Philos Trans Ser B 213:89-142

Gooch GD (1995) Territories of environmental concern. Linköping Studies in Arts and Science, Linköping University

Harrison PA, Parry ML (1993) The effect of climate change on agriculture and horticulture potential in europe. In: Climate change and impacts. European Commission, Brussels, $p$ 187-199

Hasselmann K (1990) How well can we predict the climate crisis? In: Siebert $H$ (ed) Environmental scarcity-the international dimension. J CB M ohr, Tübingen, p 165-183

Hooker NH (1907) Correlations of weather and crops. R Stat Soc J 70:1-42

IPCC (1996) IPCC second assessment report: climate change 1995. IPCC, Geneva 
Kempton W, Boster J S, Hartley J A (1995) Environmental values in A merican culture. M IT Press, Cambridge, MA

Krück C, Bray D (1999) Wie schätzen politische Experten in Deutschland die Gefahr eines globalen Klimawandels ein? Eine Meinungsumfrage zum Risikomanagement in der Umweltpolitik, GKSS 2000/6, GKSS, Geesthacht

Lohmann M (1998) Küstentourismus und Klimawandel. Prepared as part of 'Küstentourismus und Klimawandel' for the Bundesministerium für Bilding und Forschung, Berlin. Institut für Tourismus- und Bäderforschung in Nordeuropa $\mathrm{GmbH}$, Kiel

M cGovern TH (1979) The paleoeconomy of N orse Greenland: adaptation and extinction in a tightly bounded ecosystem. University Microfiles, University of Michigan, Ann Arbor

McGovern TH (1981) The economics of extinction in Norse Greenland. In: Wigley TML, Ingram MJ , Farmer G (eds) Climate and history. Cambridge University Press, Cambridge $\mathrm{p}$ 404-433

Nix HA (1985) Agriculture, Chap 5. In: Kates RW, Ausubel $\mathrm{J} \mathrm{H}$, Berberian M (eds) Climate impact assessment scope

Editorial responsibility: Hans von Storch, Geesthacht, Germany
27. J ohn Wiley and Sons, New York, p 105-130

Redclift M, Benton T (eds) (1994) Social theory and global environment. Routledge, London

Taber CS, Timpone RJ, (1996) Computational modeling. Series: Quantitative applications in the social sciences. A Sage University Paper. Sage Publications, Thousand Oaks

Valverde A J r, J acoby HD, Kaufman GM (1999) Sequential climate decisions under uncertainty: an integrated framework. Environ Model Assess 4:87-101

Vlachos E (1977) The use of scenarios for social impact assessment. In: Finsterbusch K, Wolf CP (eds) Methodology of social impact assessment. Dowden Hutchinson and Ross Inc, Strousburg, PA, p 211-223

von Storch H, Stehr N (1997b) Climate research: the case for the social sciences. Ambio 26(1):66-71

Waggoner PE (1983) Agriculture and a climate changed by more carbon dioxide. In: National Research Council, Changing Climate: Report of the Carbon Dioxide Assessment Committee. National Academy Press, Washington, DC, p 383-418

Submitted: October 20, 1999; Accepted: November 20, 1999 Proofs received from author(s): A pril 20, 2000 